\title{
Age-related trends of blood pressure levels by apolipoprotein E genotype: the Bambuì cohort study of ageing (1997-2008)
}

\author{
Maria Léa Correa Leite ${ }^{1}$, Maria Fernanda Lima-Costa ${ }^{2}$ and Emilio H Moriguchi ${ }^{3}$
}

The role of apolipoprotein E (apoE) polymorphisms in regulating blood pressure (BP) is still not clear. The aim of this study was to examine longitudinal changes in BP levels by apoE genotypes in a population-based prospective cohort of elderly subjects, and explore interactions with plasma lipids and uric acid. Subjects whose apoE genes had been genotyped at baseline (1408, representing $80.8 \%$ of all the elderly residents in Bambuì city, south-eastern Brazil; age range 60-95 years) were included in the analysis. Repeated BP measurements were obtained in four waves. Multi-level random-effects patternmixture models were used to evaluate the age-related BP trajectories, accounting for non-ignorable dropouts/deaths and handling heterogeneities as random parameter variations. Subjects with the $\varepsilon 4 / 4$ genotype and high levels of low-density lipoprotein cholesterol had higher systolic BP levels at 60 years of age than those with the other genotypes (154.5 vs. $133.2 \mathrm{~mm} \mathrm{Hg}, P=0.020$ ), but this was not the case among the older subjects. Systolic BP increased more rapidly with age in the $\varepsilon 2$ carriers, leading to significantly higher levels among the oldest. This relationship seemed to be modulated by uric acid levels, as it was present in the subjects with the $\varepsilon 2 / 3$ genotype and high uric acid levels, and in those with the $\varepsilon 2 / 4$ genotype and low or normal uric acid levels. The differences in systolic BP between the genotypes were age dependent, and the shift between the $\varepsilon 4$ and $\varepsilon 2$ alleles suggest that these alleles are involved in the different mechanisms leading to increased BP in middle-aged and elderly subjects.

Hypertension Research (2013) 36, 270-276; doi:10.1038/hr.2012.175; published online 18 October 2012

Keywords: apolipoprotein E; blood pressure; elderly; longitudinal data.

\section{INTRODUCTION}

Apolipoprotein E (apoE) is a plasma protein that has an important role in transporting cholesterol and other lipoproteins. The apoE gene is polymorphic, leading to three common alleles $(\varepsilon 2, \varepsilon 3$ and $\varepsilon 4)$ and six different genotypes $(\varepsilon 2 / 2, \varepsilon 2 / 3, \varepsilon 2 / 4, \varepsilon 3 / 3, \varepsilon 3 / 4, \varepsilon 4 / 4)$. As apoE- $\varepsilon 3$ contributes little to variations in plasma lipids, it is believed to code for normal apoE functions. Alleles $\varepsilon 2$ and $\varepsilon 4$ have a definite impact on lipid and lipoprotein levels: apoE- $\varepsilon 2$ tends to be associated with increased triglyceride levels and decreased levels of total and lowdensity lipoprotein (LDL) cholesterol, whereas apoE- $\varepsilon 4$ is associated with increased total and LDL cholesterol levels. ${ }^{1}$

ApoE has a key role in the atherosclerotic process. ${ }^{2,3}$ The $\varepsilon 4$ allele is associated with an increased risk of coronary heart disease, ${ }^{4}$ and the presence of the $\varepsilon 4$ or $\varepsilon 2$ allele in men is associated with a significantly greater cardiovascular risk. ${ }^{5}$ Nevertheless, whether apoE polymorphisms have a role in regulating blood pressure (BP) is still not clear. Some studies have suggested that high BP may be associated with the presence of the $\varepsilon 4$ allele, ${ }^{6-8}$ but a negative association has also been found, ${ }^{9}$ and others have shown an association between the $\varepsilon 2$ allele and hypertension, ${ }^{10,11}$ and yet others have found no association. ${ }^{12-14}$
These conflicting findings have recently led to a call for further investigations into gene-environment interactions to establish more clearly whether as well as which apoE alleles have a role in the development of hypertension. ${ }^{15}$ Most of the studies cited above were case-control studies, which are typically subject to significant sources of bias, whereas prospective cohort studies seem to be a more appropriate means of investigating gene-environmental interactions in complex human diseases. ${ }^{16}$ Furthermore, it has recently been pointed out that, as apoE genotypes tend to interact with some cardiovascular risk factors that tend to change with aging, there is a need for studies of older subjects that evaluate the age-related effects of apoE genotypes on cardiovascular outcomes. ${ }^{17}$

Besides plasma lipids, the levels of uric acid may be implicated in the mechanisms relating the apoE genotype and BP. Plasma uric acid has an important role in the pathogenesis of hypertension ${ }^{18}$ and its levels seem to be modulated by the apoE genotype: the $\varepsilon 2$ allele has found to be independently associated with increased levels ${ }^{19,20}$ and the $\varepsilon 4$ with decreased levels ${ }^{21}$ of plasma uric acid.

The Bambui Cohort Study of Ageing is an ongoing prospective study of an elderly Brazilian cohort, and its database, which includes

${ }^{1}$ Institute of Biomedical Technologies/CNR, National Research Council, Milan, Italy; ${ }^{2}$ Oswaldo Cruz Foundation, Rene Rachou Research Institute/Federal University of Minas Gerais Medical School, Belo Horizonte, Brazil and ${ }^{3}$ Federal University of Rio Grande do Sul/University of Vale dos Sinos/Moinho de Vento Hospital, Porto Alegre, Brazil Correspondence: Dr M Léa Correa Leite, Institute of Biomedical Technologies/CNR, National Research Council, Via Fratelli Cervi 93, 20090 Segrate, Milan, Italy. E-mail: lea.correa@itb.cnr.it

Received 14 June 2012; revised 10 August 2012; accepted 27 August 2012; published online 18 October 2012 
apoE genotyping and repeated BP measurements, offers a valuable opportunity to examine longitudinal changes in BP levels by apoE genotype and try to identify the gene-environmental interactions that could improve the development of better preventive and therapeutic strategies.

Longitudinal studies of older cohorts are complicated by the loss of individuals between waves, mainly due to death or other dropout mechanisms. If these are related to the response variable of interest, any failure to deal with dropouts can lead to biased parameter estimates and misleading inferences. ${ }^{22}$ We therefore constructed a complex multi-level random-effects pattern-mixture model to describe the time trends of systolic and diastolic BP, and here provide overall estimates for each apoE genotype and analyze the heterogeneity of the data by levels of plasma lipids and uric acid. The evaluation of these genotype-environment interactions as well as the description of their age-related dynamics denote the main novelty aspects of our study.

\section{METHODS}

\section{Subjects and measurements}

The data come from the Bambuí Cohort Study of Ageing, which involves a population-based cohort of older adults in Bambuí, a city of approximately 15000 inhabitants in south-eastern Brazil. The cohort study procedures have been described in detail elsewhere. ${ }^{23,24}$ Briefly, the baseline cohort population was identified by means of a complete census of the town performed in November and December 1996. A letter was sent to all residents (1742 individuals) aged $\geqslant 60$ years on 1 January 1997 to explain the study objectives and invite their participation. Of the 1742 eligible elderly, 1606 (92.2\%) participated in the baseline survey, which consisted of a questionnaire covering socio-demographic, lifestyle, medical and drug-use data, laboratory tests (biochemical and hematological analyses) and physical measurements (BP and anthropometric measures). The mean age of the cohort participants was 69.3 years (range $60-95$ years); $60.0 \%$ were women. Most of the participants were white $(60.4 \%), 33.2 \%$ were light brown ('moreno'), $3.7 \%$ dark brown ('mulato') and $2.7 \%$ black. The follow-up was based on annual interviews and reviews of medical records, and collected information concerning the current use of antihypertensive medication. The Bambuí Cohort Study of Ageing was approved by the Ethics Committee of the Fundação Oswaldo Cruz, Brazil, and all of the participants signed an informed consent form.

Systolic and diastolic BP were measured at baseline (1997), and after 3 (2000), 5 (2002) and 11 (2008) years of follow-up, using standard desk mercurial sphygmomanometers (Welch Allyn Tycos 5097-30, Tycos, Arden, NC, USA) and stethoscopes (Littman Cardiology II, 3M Medical Devices, St Paul, MN, USA). Either a standard adult $(12 \times 23 \mathrm{~cm})$ or a large adult $(15 \times 32 \mathrm{~cm})$ cuff size was used, appropriate to the subject's right arm circumference. At each time point, three measurements separated by 2 -min intervals were made after an initial 5-min rest, and $30 \mathrm{~min}$ or more after the last caffeine intake or last cigarette. These measurements were taken in the early morning and, to ensure adequate rest, they were performed in a quiet, isolated room with controlled temperature; the individuals were seated with the arm supported at heart level. BP was measured at the project field clinic by properly trained technicians. In this analysis, BP was considered as the arithmetic mean of the second and third measurements.

Genomic DNA for apoE genotyping was extracted from blood samples using the Wizard Genomic DNA Purification System (Promega, Madison, WI, USA). The DNA samples were then amplified by means of polymerase chain reaction (PCR), digested by HhaI and underwent restriction fragment length polymorphism analysis, as previously described. ${ }^{25}$ PCR involved the following primers: forward $5^{\prime}$-TAAGCTTGGCACGGCTGTCCAAGGA-3' and reverse $5^{\prime}$-ACAGAATTCGCCCCGGCCTGGTACAC- $3^{\prime}$. The PCR conditions were denaturation at $95^{\circ} \mathrm{C}$ for $5 \mathrm{~min}$, followed by 35 cycles of $95^{\circ} \mathrm{C}$ for $1 \mathrm{~min}$, $60{ }^{\circ} \mathrm{C}$ for $1 \mathrm{~min}$ and $70^{\circ} \mathrm{C}$ for $2 \mathrm{~min}$, and a final extension at $72^{\circ} \mathrm{C}$ for $10 \mathrm{~min}$. Restriction fragment length polymorphism analysis yielded the following patterns: $\varepsilon 2 \varepsilon 2$, 91 and $83 \mathrm{bp} ; \varepsilon 3 \varepsilon 3,91,48$ and $35 \mathrm{bp} ; \varepsilon 4 \varepsilon 4,72,48$ and $35 \mathrm{bp}$. Each of the heterozygote genotypes contained both sets of fragments from each apoE allele.
The current use of antihypertensive drugs (AHDs) was ascertained annually by reviewing medication containers and/or physician prescriptions made during home visits to all of the participants. The medications were coded on the basis of the Anatomical Therapeutic Chemical (ATC/DDD) classification system, ${ }^{26}$ and were considered AHDs if they fell into ATC groups C02 (antihypertensives), C03 (diuretics), C07 (beta-blockers), C08 (calcium channel blockers) or C09 (agents acting on the renin-angiotensin system). For the purposes of the present analysis, the subjects using any type of AHD were considered 'treated'. The participants were divided into four groups on the basis of the proportion of years on treatment in relation to the number of years of follow-up: 1 = untreated; 2 =irregularly treated (treated for less than $50 \%$ of the follow-up); $3=$ frequently treated $(\geqslant 50 \%)$; and $4=$ regularly treated.

The blood samples were drawn after a recommended 12-h fast, and plasma measurements (LDL cholesterol, HDL cholesterol, triglycerides, glucose and uric acid) were made using standard enzymatic methods (Merck KgaA, Darmstadt, Germany).

\section{Statistical analysis}

Mixed models were fitted to describe the time trends of the BP measurements. A mixed model is a statistical model that contains both fixed and random effects. The random-effects approach is a powerful means of dealing with longitudinal data sets in the presence of missing data, and provides valid inferences in the case of ignorable (random missing) non-responses. ${ }^{27}$ The term 'pattern-mixture models' describes a general class of models that deal with missing data when it is thought that dropouts cannot be ignored. ${ }^{28}$ In such models, the subjects are divided into groups on the basis of the pattern of their missing data so that their effect on outcome can be examined.

In the case of longitudinal studies, it is often reasonable to assume that intermittent missing observations are randomly missing, and recoding the patterns into groups on the basis of the last available measurement wave is a sensible option. ${ }^{29}$ By grouping subjects with similar missing patterns, we aimed to stabilize the extrapolation without losing any substantial information about the effect of 'missingness.' ${ }^{29}$

In our elderly cohort, dropouts were prevalently due to death. First of all, we defined five workable missing data pattern groups: completers, or those for whom the last measurement was available; those lost because they dropped out before or after 2002; and those lost because they died before or after 2002. We subsequently collapsed the groups with similar results and, after finding that this had a minimal effect on overall estimates, finally considered three groups: 1) completers; 2) subjects lost because they dropped out; and 3) subjects lost because of death. The variable defining these groups was included as a model covariate and, by interacting it with the genotype and time covariates, we estimated the trend parameters by each missing-pattern group.

The overall estimates were obtained by means of weighted averaging (mixing) the missing data patterns. The weights were the estimated proportions of subjects in the three missing-pattern groups within each genotype, and the s.e. of the averaged overall estimates were obtained using the delta method. ${ }^{30}$

Our models included fixed-effects intercepts for gender and treatment groups. Time trends of BP levels are expected to be influenced by AHD use and so, to avoid the problem of over-parameterisation, we addressed heterogeneity in terms of random slope parameter variations across the four treatment groups. In a hierarchical (multi-level) structure, AHD use constituted the third level: treatment groups, subjects within treatment group and BP measurements within subjects. Furthermore, the models with systolic BP as the outcome included a random slope parameter handling some of the heterogeneity between genders (a fourth level). At subject level, the random terms (intercept and slope) were assumed to have an unstructured covariance matrix in the systolic model and an independent structure in the diastolic model.

We expressed the time trends in terms of age because this is biologically more meaningful than variations over the period of follow-up time. Age at baseline was included in the models to account for birth year effects. Although this variable was associated with the dropout patterns, there were no significant interaction terms within the patterns between age at baseline and the temporal trend. The individual contributions to the age-related trends were therefore spread over a unique age axis ranging from 60 to 95 years. As the inclusion of quadratic age terms terms did not significantly improve the likelihood of the 
models, only linear terms were fitted. Examination of the residual plots did not show any particular trend in their distribution, thus indicating the good fitting of the models to the observed data.

The analyses were made using the multi-level mixed-effects linear regression (xtmixed) procedure of Stata software, version 11.2. ${ }^{31}$

\section{RESULTS}

Of the 1606 enrolled subjects, 1408 (87.7\%) underwent apoE genotyping. Only one subject had the $\varepsilon 2 / 2$ genotype and was excluded from the analysis. Of the remaining 1407, 677 (48.1\%) completed the follow-up (that is, their 2008 BP measurements were available), 195 (13.9\%) were missing because they had dropped out and 535 (38.0\%) had died (Table 1).

Table 2 shows the frequency distribution of the apoE genotypes among the 1407 subjects. The allele frequencies were within HardyWeinberg equilibrium $(P>0.10)$. There were no differences in genotype distribution between the genders $(P=0.512)$ or the AHD groups $(P=0.300)$. The age- and gender-adjusted comparisons showed that the $\varepsilon 4 / 4$ group had higher LDL cholesterol levels $(P=0.007)$ than the subjects with the $\varepsilon 3 / 3$ genotype, and those in the $\varepsilon 2 / 3(P<0.001)$ and $\varepsilon 2 / 4(P=0.003)$ had lower levels. Triglyceride levels were higher in the $\varepsilon 2 / 3$ group $(P=0.019)$ than in the $\varepsilon 3 / 3$ group. The distribution of subjects by pattern of 'missingness' was homogeneous across the apoE genotypes $(P=0.610)$. Table 3 shows mean BP levels in the four waves by genotype group.

Table 4 shows the multi-level random-effects pattern-mixture model estimates of the intercepts and slopes describing age-related trends of systolic and diastolic BP by apoE genotype. Except for the ع4/4 group, which had a negative slope (but not significantly different from zero), the estimated mean increases in systolic BP at each year of age ranged from $0.34 \mathrm{~mm} \mathrm{Hg}(\varepsilon 2 / 3, \varepsilon 3 / 3)$ to $0.96 \mathrm{~mm} \mathrm{Hg}(\varepsilon 2 / 4)$. At the age of 60 years, the subjects with the $\varepsilon 4 / 4$ genotype had higher systolic BP in comparison with the $\varepsilon 3$ carriers $(P=0.059)$. The expected diastolic BP in the $\varepsilon 3 / 3$ group at the age of 60 years was $87.4 \mathrm{~mm} \mathrm{Hg}$, and decreased by a mean of $0.35 \mathrm{~mm} \mathrm{Hg}$ with each year of age. There was no significant difference in the variation in diastolic $\mathrm{BP}$ between the apoE genotype groups.

We then explored the data for effect modifications by the plasma levels of the variables shown in Table 2, and identified heterogeneities in systolic BP trends related to LDL cholesterol and uric acid levels. Figure 1 shows the age-related trends of systolic BP estimated from the multi-level random-effects pattern-mixture model and stratified

Table 1 Patterns of missingness in relation to blood pressure measurements made in the 1407 study subjects

\begin{tabular}{|c|c|c|c|}
\hline \multirow[b]{2}{*}{ Pattern } & \multicolumn{2}{|c|}{ Missing because of } & \multirow[b]{2}{*}{ Total } \\
\hline & Dropout & Death & \\
\hline O 000 (completers) & & & 602 \\
\hline $\mathrm{OO} \mathrm{OM} \mathrm{O}$ & & & 28 \\
\hline $\mathrm{OM} \mathrm{OOO}$ & & & 35 \\
\hline $\mathrm{OM} \mathrm{M} \mathrm{O}$ & & & 12 \\
\hline Total & & & 677 \\
\hline O $00 \mathrm{M}$ (missing after the third wave) & 112 & 228 & 340 \\
\hline $\mathrm{OMOM}$ & 5 & 15 & 20 \\
\hline O O M M (missing after the second wave) & 34 & 111 & 145 \\
\hline O M M M (missing after the first wave) & 44 & 181 & 225 \\
\hline Total & 195 & 535 & \\
\hline
\end{tabular}

Abbreviations: M, missing; O, observed. on the basis of LDL cholesterol levels of $\leqslant 160 \mathrm{mg} \mathrm{dl}^{-1}$ and $>160 \mathrm{mg} \mathrm{dl}^{-1}$, after collapsing similar genotype estimates $(\varepsilon 2 / 3$, $\varepsilon 3 / 3, \varepsilon 3 / 4$ ) into a single group to make the graph easier to read. The subjects with the $\varepsilon 4 / 4$ genotype in the $\leqslant 160 \mathrm{mg} \mathrm{dl}^{-1}$ subgroup had practically constant systolic BP levels of about $134.0 \mathrm{~mm} \mathrm{Hg}$ regardless of age, whereas those in the $>160 \mathrm{mg} \mathrm{dl}^{-1}$ subgroup had higher systolic BP in the younger age groups: at the age of 60 years, the estimated systolic BP in the subjects with the $84 / 4$ genotype was $154.5 \mathrm{~mm} \mathrm{Hg}$, significantly higher than the $133.2 \mathrm{~mm} \mathrm{Hg}$ observed in the subjects with the other genotypes $(P=0.020)$. The estimated slope the $\varepsilon 2 / 4$ carriers in the low LDL cholesterol group was $1.51 \mathrm{~mm} \mathrm{Hg}$ (significantly different from zero; $P=0.025$ ) leading to expected systolic BP levels that were $16.9 \mathrm{~mm} \mathrm{Hg}$ higher than those in the $\varepsilon 3$ carriers at 80 years of age $(P=0.004)$. The estimated slope for the genotypes containing the $\varepsilon 3$ allele was $0.35 \mathrm{~mm} \mathrm{Hg}(P=0.036)$, with no significant heterogeneity between the LDL cholesterol strata. It has to be pointed out that as the high-LDL cholesterol subgroup included only four subjects with the $\varepsilon 2 / 4$ genotype and too few observations were made in the over- 80 -year olds with the $\varepsilon 4 / 4$ genotype, these are not shown in the graph.

When the data were stratified on the basis of plasma uric acid levels of $\leqslant 6 \mathrm{mg} \mathrm{dl}^{-1}$ and $>6 \mathrm{mg} \mathrm{dl}^{-1}$, there were significant differences between the subjects with genotypes containing the $\varepsilon 2$ allele (Figure 2). The expected systolic BP in the $\varepsilon 2 / 3$ carriers with low/ normal uric acid levels remained almost invariable regardless of age whereas, in those with high uric acid levels, systolic BP increased by $1.3 \mathrm{~mm} \mathrm{Hg}(P=0.001)$ for each year of age; the difference between the two slopes was significant $(P=0.002)$. At the age of 85 years, the expected systolic BP in the $\varepsilon 2 / 3$ group was $12.9 \mathrm{~mm} \mathrm{Hg}$ higher than in the $\varepsilon 3 / 3, \varepsilon 3 / 4$ groups $(P=0.036)$. Conversely, the estimated slopes in the $\varepsilon 2 / 4$ group were $1.9 \mathrm{~mm} \mathrm{Hg}(P=0.007)$ in the low/normal uric acid subgroup, and $-0.8 \mathrm{~mm} \mathrm{Hg}(P=0.362)$ in the high uric acid subgroup, a difference that was statistically significant $(P=0.013)$. The expected systolic BP in the $\varepsilon 2 / 4$ carriers with low uric acid levels was significantly higher than in the $\varepsilon 3 / 3$ or $\varepsilon 3 / 4$ groups after the age of 75 years $(P=0.004)$.

\section{DISCUSSION}

We found different age-related patterns of variations in systolic BP between the genotype groups, but no substantial heterogeneity in the variations in diastolic levels. These age-dependent differences in systolic BP between genotypes highlight the advantage of longitudinal over transversal (or cross-sectional) analysis, and may partially explain the discrepancies between studies of populations with different age ranges. It may also explain the lack of an association between apoE genotype and prevalent hypertension found in a previous transversal analysis of our data. ${ }^{32}$

The strength of our study mainly lies in its prospective nature and the large number of subjects followed for a long time. We constructed a complex statistical model to evaluate the subject-specific BP trajectories accounting for informative (non-ignorable) 'missingness'. On the other hand, the analysis was limited by intrinsic imbalances and a lack of statistical power due to the small size of some genotype groups.

The distributions of apoE alleles and genotypes in our elderly population were similar to those observed in other western populations and uninfluenced by age, thus suggesting the absence of an association with mortality. ${ }^{33}$ Although black skin color significantly correlated with the presence of two $\varepsilon 4$ alleles, an analysis excluding the dark brown or black subjects ( $5.8 \%$ of the total) led to unchanged results. 
Table 2 Apolipoprotein E genotype distribution, baseline characteristics of the study population and use of AHDs during follow-up

\begin{tabular}{|c|c|c|c|c|c|c|}
\hline & \multicolumn{5}{|c|}{ Apolipoprotein E genotype } & \multirow[b]{2}{*}{ All subjects } \\
\hline & $\varepsilon 2 / 3$ & $\varepsilon 2 / 4$ & $\varepsilon 3 / 3$ & $\varepsilon 3 / 4$ & $\varepsilon 4 / 4$ & \\
\hline Females (\%) & 58.4 & 50.0 & 61.6 & 60.2 & 48.0 & 60.5 \\
\hline \multicolumn{7}{|l|}{ Mean (s.d.) } \\
\hline Triglycerides (mg dl-1 $)$ & $167.6(144.2)$ & $132.8(51.6)$ & $147.8(92.6)$ & $154.1(97.3)$ & $145.2(74.8)$ & $151.2(100.3)$ \\
\hline HDL cholesterol (mg dl $\left.{ }^{-1}\right)$ & $50.6(16.0)$ & $60.3(23.1)$ & $49.1(14.7)$ & $48.0(14.9)$ & $50(16.2)$ & $49.2(15.1)$ \\
\hline Glucose (mg dl $\left.{ }^{-1}\right)$ & $113.4(46.9)$ & $116.6(54.7)$ & $106.3(38.4)$ & $110.3(51.2)$ & $111.0(27.9)$ & $108.2(42.7)$ \\
\hline Uric acid $\left(\mathrm{mgdl}^{-1}\right)$ & $5.2(1.7)$ & $6.0(3.8)$ & $5.4(1.7)$ & $5.2(1.5)$ & $5.2(1.9)$ & $5.3(1.7)$ \\
\hline \multicolumn{7}{|l|}{ AHD use (\%) } \\
\hline
\end{tabular}

Abbreviations: AHDs, antihypertensive drugs; HDL, high-density lipoprotein; LDL, low-density lipoprotein.

Table 3 Observed longitudinal blood pressure levels $(\mathrm{mm} \mathrm{Hg}$ ) by apolipoprotein E genotype: mean values (s.d.)

\begin{tabular}{|c|c|c|c|c|c|c|c|}
\hline \multirow[b]{2}{*}{ Year of follow-up } & & \multicolumn{5}{|c|}{ ApoE genotype } & \multirow[b]{2}{*}{ All subjects } \\
\hline & & $\varepsilon 2 / 3$ & $\varepsilon 2 / 4$ & $\varepsilon 3 / 3$ & $\varepsilon 3 / 4$ & $\varepsilon 4 / 4$ & \\
\hline \multirow[t]{2}{*}{ (baseline) } & SBP & $136.6(24.2)$ & $146.7(29.4)$ & $137.3(22.9)$ & $136.8(19.9)$ & $141.8(28.6)$ & $137.3(22.6)$ \\
\hline & DBP & $84.0(13.5)$ & $87.8(15.0)$ & 83.5 (12.6) & $83.3(12.0)$ & $86.8(16.4)$ & 83.7 (12.7) \\
\hline 2000 & DBP & 82.7 (11.6) & 89.1 (13.9) & $82.5(12.0)$ & $84.4(12.1)$ & 86.7 (16.3) & $83.1(12.1)$ \\
\hline \multirow[t]{3}{*}{2002} & $n$ & 119 & 12 & 626 & 219 & 21 & 997 \\
\hline & SBP & $135.6(20.5)$ & $139.0(15.8)$ & $137.2(21.9)$ & $137.6(20.9)$ & $136.4(29.9)$ & $137.1(21.6)$ \\
\hline & DBP & $83.9(13.1)$ & $84.2(11.1)$ & $83.6(13.7)$ & $83.4(12.5)$ & $83.5(17.0)$ & $83.6(13.4)$ \\
\hline
\end{tabular}

Abbreviations: Apo E, apolipoprotein E; DBP, diastolic blood pressure; SBP, systolic blood pressure.

Table 4 Age-related linear trends in BP measures $(\mathrm{mm} \mathrm{Hg})$ by apolipoprotein E genotype: estimated ${ }^{\mathrm{a}}$ parameters $(95 \%$ confidence interval)

\begin{tabular}{|c|c|c|c|c|}
\hline \multirow[b]{2}{*}{ Genotype } & \multicolumn{2}{|c|}{ Systolic BP } & \multicolumn{2}{|c|}{ Diastolic BP } \\
\hline & Intercept ${ }^{b}$ & Slope & Intercept ${ }^{b}$ & Slope \\
\hline$\varepsilon 2 / 4$ & $133.1(115.7,150.6)$ & $0.96(-0.13,2.04)$ & $91.8(81.9,101.7)$ & $-0.37(-0.97,0.23)$ \\
\hline$\varepsilon 3 / 3$ & $133.6(130.9,136.2)$ & $0.34(0.02,0.66)$ & $87.4(85.9,88.9)$ & $-0.35(-0.52,-0.18)$ \\
\hline$\varepsilon 3 / 4$ & $133.2(129.3,137.0)$ & $0.45(0.08,0.82)$ & $86.9(84.8,89.1)$ & $-0.31(-0.51,-0.11)$ \\
\hline
\end{tabular}

Abbreviation: BP, blood pressure.

ausing multi-level mixed-effects pattern-mixture models as described in the text.

aUsing multi-level mixed-effects
bValues at age of 60 years.

cMean variation in BP levels with each year of age. 

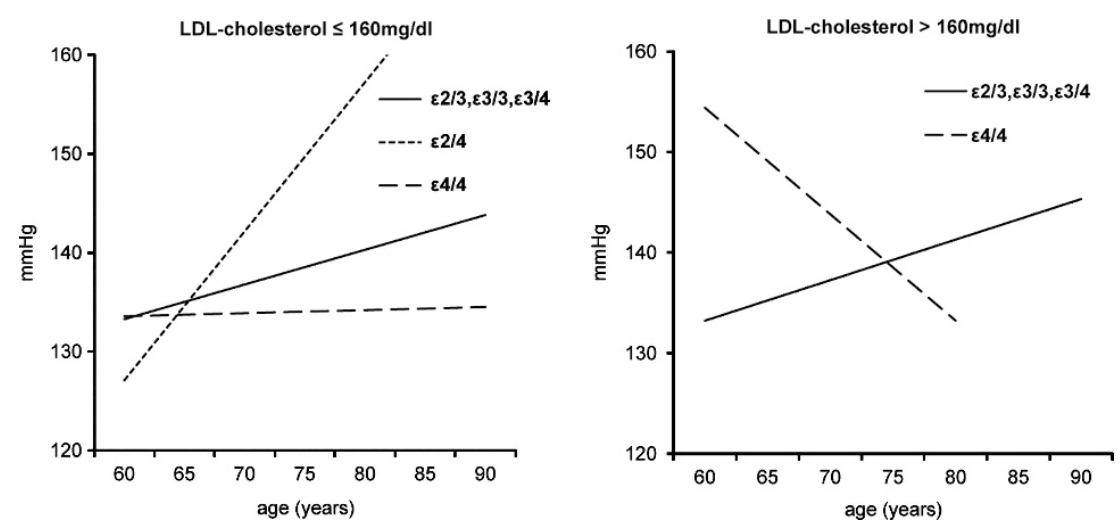

Figure 1 Age-related trends of systolic blood pressure by apolipoprotein E genotype and plasma low-density lipoprotein (LDL) cholesterol level.
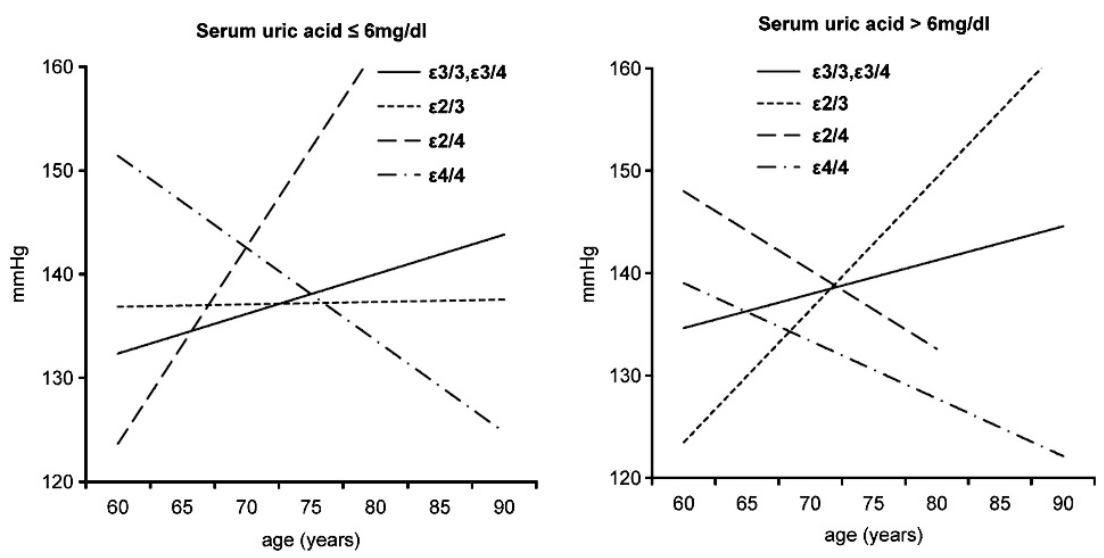

Figure 2 Age-related trends of systolic blood pressure by apolipoprotein E genotype and plasma uric acid level.

We found that the younger carriers of the $\varepsilon 4 / 4$ genotype (that is, those aged about 60 years) had significantly higher systolic BP than the other groups. This is consistent with the results of two recent meta-analyses (one of which considered only Chinese subjects) ) $^{34,35}$ showing that the apoE $\varepsilon 4$ allele was associated with an increased risk of developing hypertension in a recessive manner. After stratification by LDL cholesterol $\leqslant 160 \mathrm{mg} \mathrm{dl}^{-1}$ and $>160 \mathrm{mg} \mathrm{dl}^{-1}$, only the $\varepsilon 4 / 4$ subjects in the latter group had high systolic BP at the age of 60 years. This may be due to the fact that the $\varepsilon 4$ allele may be a common genetic determinant of both hypercholesterolemia and systolic hypertension. ${ }^{6}$ A twin study examining the relative contributions of genetics and the environment to the association between BP and serum lipid levels observed a significant genetic covariance between LDL cholesterol and systolic BP. ${ }^{36}$ However, the fact that the high systolic BP values were confined to the group with high LDL cholesterol suggests that hypercholesterolemia may form part of the pathway linking the $\varepsilon 4 / 4$ genotype to systolic hypertension. It has been found that LDL cholesterol increases vascular responsiveness to angiotensin $\mathrm{II}^{37,38}$ by increasing the number of receptors mediating its action, ${ }^{39}$ which directly raises peripheral vascular resistance and predisposes to hypertension. The $\varepsilon 4$ allele has less impact on LDL cholesterol levels in more elderly groups ${ }^{40}$ and this may partially explain the looser association between the $\varepsilon 4 / 4$ genotype and high systolic BP after the age of 70 years.

The more rapid increases in systolic BP in the $\varepsilon 2 / 4$ group led to significantly higher BP levels in the oldest age group. The rare $\varepsilon 2 / 4$ genotype seems to characterize a special group of subjects but, unfortunately, they were too few to allow more precise conclusions. Given the opposite effect of their alleles on lipids, this group is often excluded from analyses, but it has been shown that the $\varepsilon 2$ allele is dominant and has a larger impact than the $\varepsilon 4$ allele. $^{41}$

Serum uric acid levels seem to modulate longitudinal changes in systolic BP in carriers of the $\varepsilon 2$ allele, but the subjects with the $\varepsilon 2 / 3$ genotype and high uric acid levels showed a significantly more rapid increase in systolic BP than those with low/normal levels, and the opposite was found in the subjects with the $\varepsilon 2 / 4$ genotype. High uric acid levels in subjects with the $\varepsilon 2 / 3$ genotype indicate a subgroup with a higher prevalence of obesity and dyslipidemia (high triglyceride, and low-HDL cholesterol levels), thus suggesting that the more rapid agerelated increase in systolic BP was related to a 'metabolic syndrome' context. On the contrary, there were no obese subjects in the $\varepsilon 2 / 4$ genotype group and those with normal/low uric acid levels tended to have higher levels of glucose and triglycerides than those with high uric acid levels (data not shown). The triglyceride-raising effect of the $\varepsilon 2$ allele has been widely shown ${ }^{42}$ but, unlike that of LDL cholesterol, the role of plasma triglycerides as an independent cardiovascular risk factor is somewhat controversial. ${ }^{43}$

It has been suggested that the presence of the $\varepsilon 2$ allele in an 'unhealthy environment' may predispose an individual to increased levels of triglyceride-rich lipoproteins, commonly called remnant lipoproteins, ${ }^{44}$ whose significant role in the pathogenesis of 
atherosclerosis is becoming increasingly clear. ${ }^{45}$ Growing evidence supports their role in the pathophysiology of vascular disease, ${ }^{46}$ as high concentrations of triglyceride-rich lipoproteins are a strong predictor of arterial stiffness in women. ${ }^{47}$ It has been found that remnant lipoproteins impair endothelium-dependent vasomotor function in large coronary arteries ${ }^{48}$ and, interestingly, that this dysfunction is independently and intimately associated with pulse pressure. ${ }^{49}$ It has been suggested that oxidative stress is the underlying mechanism relating these disorders, ${ }^{50}$ and it is known to be the mechanism causing the large arterial alterations (stiffness and decreased compliance) involved in the pathophysiology of geriatric hypertension. ${ }^{51}$ It has also been suggested that uric acid acts as a pro-oxidant in the context of the metabolic syndrome, ${ }^{50}$ may have pro-inflammatory effects on vascular cells ${ }^{52}$ and induces oxidative stress in adipocytes, ${ }^{53}$ but it may function as an anti-oxidant. ${ }^{54}$ C-reactive protein (CRP) is an inflammatory marker associated with both oxidative stress ${ }^{55}$ and arterial stiffness ${ }^{56}$ and, interestingly, our uric acid data positively correlated with CRP and triglyceride levels in the subjects with the $\varepsilon 2 / 3$ genotype, but negatively correlated with them in the subjects with the $\varepsilon 2 / 4$ genotype (data not shown).

We found an age-related shift between the $\varepsilon 4$ and the $\varepsilon 2$ alleles that influenced systolic BP. It is likely that these alleles act by means of different mechanisms with different time courses during life, as the $\varepsilon 4$ allele is involved in the mechanisms participating in the development of hypertension in the middle-aged, and the $\varepsilon 2$ allele is involved in the mechanisms prevalently related to hypertension in the elderly. High systolic BP is a well-established risk factor for stroke in the elderly, ${ }^{57}$ and the genes modifying the risk of hypertension could also influence the risk of stroke. Like those regarding hypertension, studies of the association between apoE and stroke remain controversial. ${ }^{58}$ However, it is interesting to note some analogies between our results and those of a study of a Japanese rural population aged 40-89 years that evaluated the association between apoE polymorphisms and stroke. ${ }^{59}$ This study showed that the association between $\varepsilon 2$ carriers and stroke was more marked in the elderly than in the middle-aged. The apoE $\varepsilon 2$ carriers tended to have an increased age-related odds ratio for all strokes, whereas the $\varepsilon 4$ carriers tended to show the opposite effect. The association between apoE polymorphisms and coronary artery disease is also influenced by age, ${ }^{60}$ with carriers of the $\varepsilon 3 / 4$ genotype suffering myocardial infarction at an earlier age than carriers of the $\varepsilon 2 / 3$ genotype.

In conclusion, our findings show that increased systolic BP is associated with the presence of two $\varepsilon 4$ alleles and high-LDL cholesterol levels in middle-aged subjects, and that this relation disappeared in the elderly. Among the older subjects, $\varepsilon 2$ carriers had increasingly higher systolic BP. Uric acid levels seem to discriminate subgroups at increased risk of systolic hypertension among the subjects with different genotypes containing the $\varepsilon 2$ allele and, together with apoE genotyping, determining its serum concentration could be helpful when preparing preventive action.

\section{CONFLICT OF INTEREST}

The authors declare no conflict of interest.

\section{ACKNOWLEDGEMENTS}

We thank Dr M Taufer (CMIC Brazil Clinical Research Laboratory, Porto Alegre, Brazil) for ApoE genotyping. This study was supported by a grant from the Italian National Council (CNR) in the ambit of the Bilateral Agreement of Scientific Coopertaion CNR-CNPq (Brazil).
1 Mahley RW, Rall SC. Apolipoprotein E: far more than a lipid transport protein. Annu Rev Genomics Hum Genet 2000; 1: 507-537.

2 Davignon J. Apolipoprotein E and atherosclerosis. Arterioscler Thromb Vasc Biol 2005; 25: 267-269.

3 Raffai RL, Loeb SM, Weisgraber KH. Apolipoprotein E promotes the regression of atherosclerosis independently of lowering plasma cholesterol levels. Arterioscler Thromb Vasc Biol 2005; 25: 436-441.

4 Song Y, Stampfer MJ, Liu S. Meta-analysis: apolipoprotein E genotypes and risk for coronary heart disease. Ann Intern Med 2004; 141: 137-147.

5 Lahoz C, Schaefer EJ, Cupples A, Wilson PWF, Levy D, Osgood D, Parpos S, PedroBotet J, Daly JA, Ordovas JM. Apolipoprotein E genotype and cardiovascular disease in the Framingham Heart Study. Atherosclerosis 2001; 154: 529-537.

6 Ruixing Y, Jinzhen W, Weixiong L, Yuming C, Dezhai Y, Shangling P. The environmental and genetic evidence for the association of hyperlipidemia and hypertension. J Hypertens 2009; 27: 251-258.

7 Bhavani AB, Sastry KB, Reddy NK, Pdma T. Lipid profile and apolipoprotein E polymorphisms in essential hypertension. Indian Heart J 2005; 57: 151-157.

8 Li X, Du Y, Du Y, Huang X. Association of apolipoprotein E gene polymorphisms with essential hypertension and its complications. Clin Exp Med 2003; 2: 175-179.

9 Katsuya T, Baba S, Ishikawa K, Mannami T, Fu Y, Inamoto N, Asai T, Fukuda M, Higaki $\mathrm{J}$, Ogata J, Ogihara T. Epsilon 4 allele of apolipoprotein $\mathrm{E}$ gene associates with lower blood presure in young Japanese subjects: the Suita Study. J Hypertens 2002; 20: 2017-2021.

10 Imazu M, Yamamoto H, Toyofuku M, Watanabe T, Okubo M, Egusa G, Yamakido M, Kohno N. Association of apolipoprotein E phenotype with hypertension in JapaneseAmericans: data from the Hawaii-Los Angeles-Hiroshima Study. Hypertens Res 2001; 24: 523-529.

11 Couderc R, Mahieux F, Beilleul S, Fenelon G, Mary R, Fermanian J. Prevalence of apolipoprotein $E$ phenotypes in ischemic cerebrovascular disease. A case-control study. Stroke 1993; 24: 661-664.

12 de Knijff P, Boomsma DL, Feskens EJM, Jespersen J, Johansen LG, Kluft C, Kromhout D, Havekes LM. Apolipoprotein E and blood pressure. Lancet 1994; 343: 1234.

13 Wilson PW, Myers RH, Larson MG, Ordovas JM, Wolf PA, Schaefer EJ. Apolipoprotein E alleles, dyslipidemia, and coronary heart disease: The Framingham Offspring Study. JAMA 1994; 272: 1666-1671.

14 Rastas S, Mattila K, Verkkoniemi A, Niinisto L, Juva K, Sulkava R, Lansimier E. Association of apolipoprotein $E$ genotypes, blood pressure, blood lipid and ECG abnormalities in a general population aged $85+$. BMC Geriatr 2004; 4: 1 .

15 Hamet P. Apolipoprotein E alleles and hypertension: controversy or lack of understanding? J Hypertens 2002; 20: 1941-1942.

16 Manolio TA, Bailey-Wilson JE, FS Collins. Genes, environment and the value of prospective cohort studies. Nature Rev Genet 2006; 7: 812-820.

17 Haan MN, Mayeda ER. Apolipoprotein E genotype and cardiovascular disease in the elderly. Curr Cardio Risk Rep 2010; 4: 361-368.

18 Johnson RJ, Kang D-H, Feig D, Kivlighn S, Kanellis J, Watanabe S, Tuttle KR, Rodriguez-Iturbe B, Herrera-Acosta J, Mazzali M. Is there a pathogenetic role for uric acid in hypertension and cardiovascular and renal disease? Hypertension 2003; 41: 1183-1190.

19 Liberopoulos EN, Miltiadous GA, Athyros VG, Ganotakis M, Cariolou M, Bairaktari E, Elisaf MS. Effect of apolipoprotein E polymorphism on serum uric acid levels in healthy subjects. J Investig Med 2005; 53: 116-122.

20 Cardona F, Tinahones FJ, Collantes E, Escudero A, Garcia-Fuentes E, Soriguer FJ. The elevated prevalence of apolipoprotein E2 in patients with gout is associated with reduced renal excretion of urates. Rheumatology 2003; 42: 468-472.

21 Fernandes MA, Proença MT, Nogueira AJ, Grazina MM, Oliveira LM, Fernandes AI, Santiago B, Santana I, Oliveira CR. Influence of apolipoprotein E genotype on blood redox status of Alzheimer's disease patients. Int J Mol Med 1999; 4: 179-186.

22 Hogan JW, Roy J, Korkontzelou C. Handling drop-outs in longitudinal studies. Statist Med 2004; 23: 1455-1497.

23 Lima-Costa MF, Firmo JOA, Uchoa E. The Bambuì Cohort Study of Ageing: methodology and health profile of participants at baseline. Cad Saude Publica 2011; 27(Suppl 3): S327-S335.

24 Lima-Costa MF, Firmo JOA, Uchoa E. Cohort profile: the Bambuí (Brazil) cohort study of ageing. Int J Epidemiol 2011; 40: 862-867.

25 Hixson JE, Vernier DT. Restriction isotyping of human apolipoprotein $E$ by gene amplification and cleavage with Hhal. J Lipid Res 1990; 31: 545-548.

26 WHO Collaborating Centre for Drug Statistics Methodology. Guidelines for ATC Classification and DDD Assignment 2010. WHO, Oslo, 2009, p 282. Available from http://www. whocc.no/filearchive/publications/2010guidelines.pdf.

27 Laird NM. Missing data in Iongitudinal studies. Statist Med 1988; 7: 305-315.

28 Hedeker D, Gibbons RD. Application of random-effects pattern-mixture models for missing data in longitudinal studies. Psychol Methods 1997; 2: 64-78.

29 Demirtas H, Schafer JL. On the performance of random-coefficient pattern-mixture models for non-ignorable drop-out. Statist Med 2003; 22: 2553-2575.

30 Hogan JW, Laird NM. Mixture models for the joint distribution of repeated measures and event times. Statist Med 1997; 16: 239-258.

31 StataCorp. Stata: Release 11. Statistical SoftwareStataCorp LP, College Station, TX, 2009.

32 Fuzikawa AK, Peixoto SV, Taufer M, Moriguchi EH, Lima-Costa MF. Association of ApoE polymorphisms with prevalent hypertension in 1406 older adults: the Bambui Health Aging Study (BHAS). Braz J Med Biol Res 2008; 41: 89-94. 
33 Fuzikawa AK, Peixoto SV, Taufer M, Moriguchi EH, Lima-Costa MF. Apolipoprotein E polymorphism distribution in an elderly Brazilian population: the Bambui Health and Aging Study. Braz J Med Biol Res 2007; 40: 1429-1434.

34 Niu W, Qi Y, Qian Y, Gao P, Zhu D. The relationship between apolipoprotein E epsilon2/epsilon3/epsilon4 polymorphisms and hypertension: a meta-analysis of six studies comprising 1812 cases and 1762 controls. Hypertens Res 2009; 32: 1060-1066.

35 Niu W-Q, Qi Y. Meta-based evidence for apolipoprotein E $\varepsilon 2 / \varepsilon 3 / \varepsilon 4$ polymorphisms in association with hypertension among Chinese. J Hum Hypertens 2011; 25: 725-731.

36 Williams PD, Puddey IB, Martin NG, Beilin LJ. Genetic and environmental covariance of serum cholesterol and blood pressure in female twins. Atherosclerosis 1993; 100: 19-31.

37 John S, Delles C, Klingbeil AU, Jacobi J, Schlaich MP, Schmieder RE. Low-density lipoprotein-cholesterol determines vascular responsiveness to angiotensin II in normocholesterolaemic humans. J Hypertens 1999; 17: 1933-1939.

38 Van der Linde NA, Sijbrands EJ, Boomsma F, van den Meiracker AH. Effect of lowdensity lipoprotein cholesterol on angiotensin II sensitivity: a randomized trial with fluvastatin. Hypertension 2006; 47: 1125-1130.

39 Nickenig G, Sachinidis A, Michaelsen F, Bohm M, Seewald S, Vetter H. Upregulation of vascular angiotensin II receptor gene expression by low-density lipoprotein in vascular smooth muscle cells. Circulation 1997; 95: 473-478.

40 Jarvik GP, Austin MA, Fabsitz RR, Auwerx J, Reed T, Christian JC, Deeb S. Genetic influences on age-related change in total cholesterol, low density lipoprotein-choles terol, and triglyceride levels: longitudinal apolipoprotein E genotype effects. Genet Epidemiol 1994; 11: 375-384.

41 Bohnet K, Regis-Bailly A, Vincent-Viry M, Schlenck A, Gueguen R, Siest G, Visvikis S. Apolipoprotein E genotype epsilon 4/epsilon 2 in the STANISLAS Cohort Study: dominance of the epsilon 2 allele? Ann Hum Genet 1996; 60: 509-516.

42 Dallongeville J, Lussier-Cacan S, Davignon J. Modulation of plasma triglyceride levels by apoE phenotype: a meta-analysis. J Lipid Res 1992; 3: 447-454.

43 Gandotra P, Miller M. The role of triglycerides in cardiovascular risk. Curr Cardiol Rep 2008; 10: 505-511.

44 Davignon J, Cohn JS, Mabile L, Bernier L. Apolipoprotein E and atherosclerosis: insight from animal and human studies. Clin Chim Acta 1999; 286: 115-143.

45 Twickler T, Dallinga-Thie GM, Chapman MJ, Cohn JS. Remnant lipoproteins and atherosclerosis. Curr Atheroscler Rep 2005; 7: 140-147.

46 Haynes WG. Triglyceride-rich lipoproteins and vascular function. Arterioscler Thromb Vasc Biol 2003; 23: 153-155.

47 Le N-A, Brown WV, Davis WW, Herrington DM, Mosca L, Homma S, Eggleston B, Willens $\mathrm{H}$, Raines JK. Comparison of the relation of triglyceride-rich lipoproteins and muscular artery compliance in healthy women versus healthy men. Am J Cardiol 2005; 95: 1409-1054.
48 Kugiyama K, Doi H, Motoyama T, Soejima H, Misumi K, Kawano H, Nakagawa O, Yoshimura M, Ogawa H, Matsumura T, Sugiyama S, Nakano T, Nakajima K, Yasue H. Association of remnant lipoprotein levels with impairment of endotheliumdependent vasomotor function in human coronary arteries. Circulation 1998; 97 : 2519-2526.

49 Ichigi Y, Takano H, Umetani K, Kawabata K, Obata J, Kitta Y, Kodama Y, Mende A, Nakamura T, Fujioka D, Saito Y, Kugiyama K. Increased ambulatory pulse pressure is a strong risk factor for coronary endothelial vasomotor dysfunction. J Am Coll Cardiol 2005; 45: 1461-1466.

50 Koenig W, Meisinger C. Uric acid, type 2 diabetes, and cardiovascular diseases: fueling the common soil hypothesis? Clin Chem 2008; 54: 231-233.

51 Solhaug MJ. Pathophysiological role for oxidative stress in geriatric vascular dysfunction. Am J Physiol Regul Integr Comp Physiol 2003; 285: R524-R525.

52 Kang DH, Park SK, Lee IK, Johnson RJ. Uric acid-induced C-reactive protein expression: implication on cell proliferation and nitric oxide production of human vascular cells. J Am Soc Nephrol 2005; 16: 3553-3562.

53 Sautin YY, Nakagawa T, Zharikov S, Johnson RJ. Adverse effects of the classic antioxidant uric acid in adipocytes: NADPH oxidase-mediated oxidative/nitrosative stress. Am J Physiol Cell Physiol 2007; 293: C584-C596.

54 Feig DI, Kang D-H, Johnson RJ. Uric acid and cardiovascular risk. N Engl J Med 2008; 359: 1811-1821.

55 Abramson JL, Hooper WC, Jones DP, Ashfaq S, Rhodes SD, Weintraub WS, Harrison DG, Quyyumi AA, Vaccarino V. Association between novel oxidative stress markers and C-reactive protein among adults without clinical coronary heart disease. Atherosclerosis 2005; 178: 115-121.

56 Duprez DA, Somasundaram PE, Sigurdsson G, Hoke L, Florea N, Cohn JN. Relationship between C-reactive protein and arterial stiffness in an asymptomatic population. J Hum Hypertens 2005; 19: 515-519.

57 Psaty BM, Furberg CD, Kuller LH, Cushman M, Savage PJ, Levine D, O'Leary DH Bryan RN, Anderson M, Lumley T. Association between blood pressure level and the risk of myocardial infarction, stroke, and total mortality: the cardiovascular health study. Arch Intern Med 2001; 161: 1183-1192.

58 Sudlow C, Gonzalez NAM, Kim J, Clark C. Does apolipoprotein E genotype influence the risk of ischemic stroke, intracerebral hemorrhage, or subarachnoid hemorrhage? Stroke 2006; 37: 364-370.

59 Kokubo Y, Chowdhury AH, Date C, Yokoyama T, Sobue H, Tanaka H. Age-dependent association of apolipoprotein $\mathrm{E}$ genotypes with stroke subtypes in a Japanese rural population. Stroke 2000; 31: 1299-1306.

60 Lenzen HJ, Assmann G, Buchwalaky R, Schulte H. Association of apolipoprotein E polymorophisms, low-density lipoprotein cholesterol, and coronary artery disease. Clin Chem 1986; 32: 778-781. 